\title{
Laboratory Validation of Instrumented Mouthguard for Use in Sport
}

\author{
Danyon Stitt ${ }^{1}{ }^{\circledR}$, Nick Draper $^{2, *}$, Keith $^{\text {Alexander }}{ }^{1}$ and Natalia Kabaliuk ${ }^{1}[$ \\ 1 Department of Mechanical Engineering, University of Canterbury, Christchurch 8041, New Zealand; \\ danyon.stitt@pg.canterbury.ac.nz (D.S.); keith.alexander@canterbury.ac.nz (K.A.); \\ natalia.kabaliuk@canterbury.ac.nz (N.K.) \\ 2 School of Health Sciences, University of Canterbury Christchurch, Christchurch 8041, New Zealand \\ * Correspondence: nick.draper@canterbury.ac.nz; Tel.: +64-3-369-3878
}

check for updates

Citation: Stitt, D.; Draper, N.;

Alexander, K.; Kabaliuk, N.

Laboratory Validation of

Instrumented Mouthguard for Use in

Sport. Sensors 2021, 21, 6028.

https://doi.org/10.3390/s21186028

Academic Editor: Vittorio

M.N. Passaro

Received: 10 August 2021

Accepted: 3 September 2021

Published: 9 September 2021

Publisher's Note: MDPI stays neutral with regard to jurisdictional claims in published maps and institutional affiliations.

Copyright: (c) 2021 by the authors. Licensee MDPI, Basel, Switzerland. This article is an open access article distributed under the terms and conditions of the Creative Commons Attribution (CC BY) license (https:// creativecommons.org/licenses/by/ $4.0 /)$.

\begin{abstract}
Concussion is an inherent risk of participating in contact, combat, or collision sports, within which head impacts are numerous. Kinematic parameters such as peak linear and rotational acceleration represent primary measures of concussive head impacts. The ability to accurately measure and categorise such impact parameters in real time is important in health and sports performance contexts. The purpose of this study was to assess the accuracy of the latest HitIQ Nexus A9 instrumented mouthguard (HitIQ Pty. Ltd. Melbourne Australia) against reference sensors in an aluminium headform. The headform underwent drop testing at various impact intensities across the NOCSAE-defined impact locations, comparing the peak linear and rotational acceleration (PLA and PRA) as well as the shapes of the acceleration time-series traces for each impact. Mouthguard PLA and PRA measurements strongly correlated with $\left(\mathrm{R}^{2}=0.996\right.$ and 0.994 respectively), and strongly agreed with $(\mathrm{LCCC}=0.997)$ the reference sensors. The root mean square error between the measurement devices was $1 \pm 0.6 \mathrm{~g}$ for linear acceleration and $47.4 \pm 35 \mathrm{rad} / \mathrm{s}^{2}$ for rotational acceleration. A Bland-Altman analysis found a systematic bias of $1 \%$ for PRA, with no significant bias for PLA. The instrumented mouthguard displayed high accuracy when measuring head impact kinematics in a laboratory setting.
\end{abstract}

Keywords: instrumented mouthguard; head impacts; concussion; accelerations; sports

\section{Introduction}

Concussion is an inherent risk of participating in contact, combat, or collision sports. All attract high numbers of participants, with over 23 million registered participants internationally [1-5]. Given the high intensity of these sports, injuries are common, with concussions being one of the most common. One study estimated as many as 300,000 sportsrelated concussions occur annually in the US alone [6], creating an associated economic burden of USD 60 billion annually [7]. Numerous researchers have investigated concussion rates, and reports vary, with 0.5-250.6/1000 athlete exposures (AE) [8-17]. An AE is defined as one person participating in one game or match. For example, one boxing match has two AEs.

When the head experiences an impact, the varied density causes parts of the brain to accelerate at different rates, deforming the tissue [18]. The brain can handle some deformation; however, once a certain threshold is surpassed, trauma occurs, eliciting a variety of biological responses [18]. Impacts over $10 \mathrm{~g}$ not resulting in acute concussion symptoms have been labelled subconcussive impacts [19]. It has been suggested that combinations of concussive and subconcussive head impacts may result in long-term conditions such as chronic traumatic encephalopathy [20], cognitive impairment [21], and depression [22]. Most concussions go unreported until symptoms show, which can be up to a few days [23], meaning a large number are not identified until 24 hours or more after the injury $[24,25]$. Additionally, reports suggest that approximately $90 \%$ of concussions do 
not result in a loss of consciousness [23,26], further complicating on-field diagnosis. As a result, underreporting rates are estimated to be as high as 50-90\% [26]. For 80 to $90 \%$ of cases, the individual's symptoms resolve within 2 weeks $[25,27-30]$, although recovery appears to be slower for adolescents than college-age athletes [28,31-33].

In an ideal case, assessment of injured players is facilitated by a certified athletic trainer, team physician, or health care provider on the sideline; however, the vast majority of young athletes practice and play in circumstances in which trained personnel are not immediately available [18]. In New Zealand, sporting guidelines state that players suspected to have sustained a concussive injury are to be removed from play immediately and monitored for symptoms [23]. This method relies upon the player correctly reporting the immediate symptoms, which hinders effectiveness, as there is a tendency for athletes to underreport their symptoms [34-36].

Wearable sensor technology exists that can report real-time impact information. The most common types are helmet-integrated sensors, patch sensors, and mouthguard sensors, all of which measure peak linear acceleration (PLA), rotational velocity (PRV), and/or rotational acceleration (PRA). The first is the head-impact telemetry (HIT) system, finding common use in studies of American football or ice hockey. Using a 12-accelerometer array embedded rigidly in hard-shelled helmets, accuracy of the device depends on the fit of the helmet [37,38]. Patch and mouthguard sensors can be used in unhelmeted sports such as football or rugby. Patch sensors are secured on the skin using an adhesive or a headband, and are commonly placed over the mastoid process behind the ear [37]. They measure head impacts using three linear accelerometers and a triaxial angular rate sensor. Laboratory validation studies have found the patch sensors to perform poorly. One study found the X-patch to have an error rate of up to 50\% for PLA and PRA [39], with another finding the patch to underestimate PRA by more than $25 \%$ on average [40]. A 2017 study found the patch to have root mean square (RMS) errors of $34 \%$ for PLA and $23.4 \%$ for PRA [41].

In vivo validation studies have reported similar results. Both patch and headband sensors showed large errors due to slipping over the skull with the skin, giving false acceleration values [42]. This study reported movements during impacts of $2-4 \mathrm{~mm}$ for the patch sensors and 2-13 $\mathrm{mm}$ for the headband sensor, while the mouthguard sensor showed far less movement $(<1 \mathrm{~mm})$ relative to a marker secured in the ear [42]. Additionally, video validation found the $X$-patch had a positive predictive value of $16.3 \%$ for head impacts [42]. Comparatively, a laboratory validation study of the X2 mouthguard reported average RMS errors of $9.9 \pm 4.4 \%$ for linear acceleration (LA) and $9.7 \pm 7 \%$ for rotational acceleration (RA) [43]. However, the X2 performed poorly when estimating impact directions [44].

A new instrumented mouthguard, the HitIQ Nexus A9, has recently been developed by HitIQ Pty Ltd. The Nexus A9 boasts two independent measurements of rotational kinematics, which may allow the mouthguard to display increased accuracy and dynamic range of angular kinematic estimates. However, being relatively new to the market, this mouthguard currently lacks validation in a laboratory setting. Instrumented mouthguards have been shown to produce lower errors and have better coupling to the head compared to other systems, thus proving to be the best method for identifying concussive impacts during gameplay. The purpose of this study is therefore to assess the accuracy of the HitIQ Nexus A9 instrumented mouthguard in a controlled laboratory setting. This will be achieved by comparing the PLA and PRA values and shapes of the acceleration time-series traces of the mouthguard sensor to a reference accelerometer pack inside a 50th-percentile ATD headform.

\section{Materials and Methods}

\subsection{Experimental Procedure}

Testing was carried out using a gravity-induced, twin-wire-guided drop-test rig. An electromagnet lifted and held the drop carriage shown in Figure 1, then released it from the specified height. The impact locations were: front, front boss, side, rear, and rear boss, as described by the NOCSAE standard [45] (Figure 1). The headform used was based on 
the Hybrid III 50th-percentile male headform (Humanetics group, Farmington Hills, MI, USA.), modified to include a rigidly fastened dentition (Figure 1). This headform was made of aluminium and excluded the rubber skin cover found on the Hybrid III headform. The neckform used was a Hybrid III neckform replica.

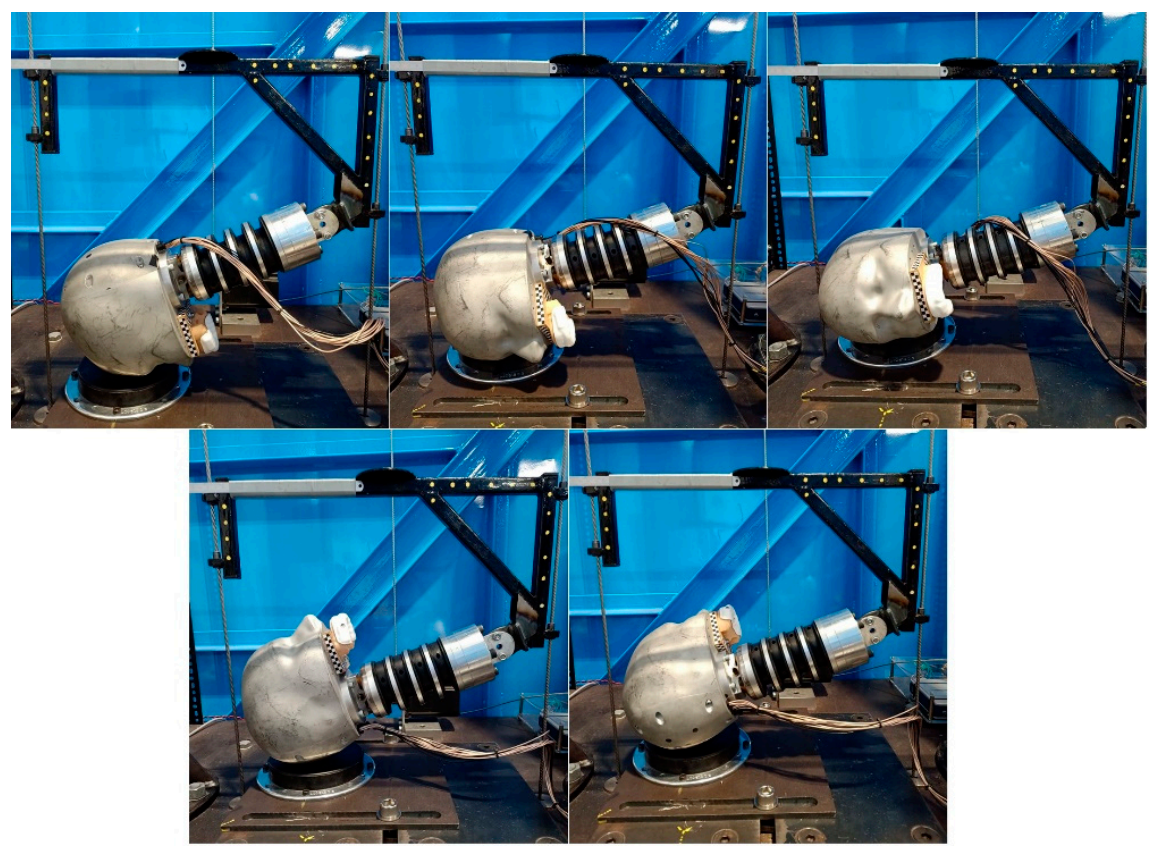

Figure 1. Impact locations, from top left to bottom right: front/forehead, front boss, side, rear, and rear boss. The mouthguard and dentition are both shown rigidly fixed to the upper jaw of the ATD headform.

Drop heights were established to achieve PLAs of 20, 40, and $80 \mathrm{~g}$; these were chosen because they fell within the range of published data for sporting head impacts [10,46-50]. Three impact durations for the LA time-series traces were targeted. These were 15, 30, and $60 \mathrm{~ms}$, to represent short-, medium-, and long-duration head-acceleration events, respectively (Table 1). Test durations were defined based on a threshold LA of $20 \%$ of the PLA on either side of the peak (Figure 2a). Certain high-energy impact scenarios were not performed due to the likelihood of damaging components.

The headform was dropped onto a 1 inch modular elastomer programmer pad (Cadex Inc., Quebec, QC, Canada), which was chosen because it displays a similar impact response across a wide range of strain rates, and is commonly used throughout the literature. On top of this pad, various combinations of foam were placed to achieve the desired PLAs and durations. Foam combinations were coded A-L for ease of display; detailed lists can be found in Appendices A and B. Drop heights were taken from the top of the impact surface to the lowest point of the headform when attached to the drop carriage. Each test impact scenario was repeated five times.

Table 1. Drop heights $(\mathrm{m})$ and foam combination (A-L) (Appendices A and B) for each impact scenario tested. Those unable to be tested are left blank.

\begin{tabular}{ccccccc}
\hline PLA (g) & Duration (ms) & Forehead & Front Boss & Side & Rear & Rear Boss \\
\hline \multirow{2}{*}{$20 \mathrm{~g}$} & $15 \mathrm{~ms}$ & $0.05(\mathrm{E})$ & $0.11(\mathrm{~A})$ & $0.08(\mathrm{E})$ & $0.06(\mathrm{~L})$ & $0.08(\mathrm{I})$ \\
& $30 \mathrm{~ms}$ & $0.39(\mathrm{C})$ & $0.46(\mathrm{C})$ & $0.60(\mathrm{C})$ & $0.51(\mathrm{C})$ & $0.53(\mathrm{C})$ \\
& $60 \mathrm{~ms}$ & $1.16(\mathrm{H})$ & $1.04(\mathrm{H})$ & - & - & - \\
$40 \mathrm{~g}$ & $15 \mathrm{~ms}$ & $0.14(\mathrm{~F})$ & $0.24(\mathrm{~B})$ & $0.20(\mathrm{~F})$ & $0.15(\mathrm{~L})$ & $0.17(\mathrm{~F})$ \\
$80 \mathrm{~g}$ & $30 \mathrm{~ms}$ & $0.64(\mathrm{~J})$ & $1.60(\mathrm{D})$ & - & - & - \\
\hline
\end{tabular}




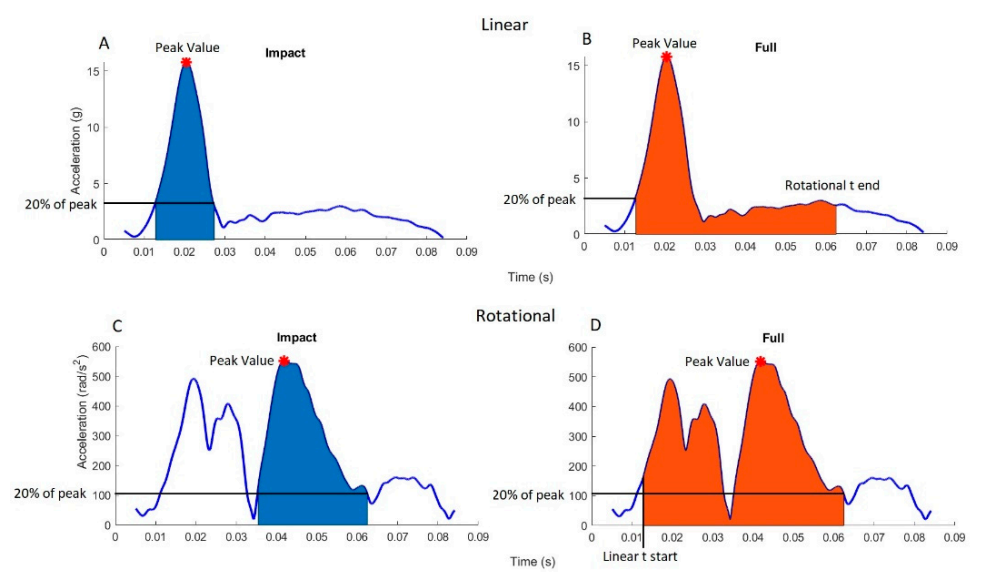

Figure 2. Time periods considered for the RMS calculations, with Impact $(\mathbf{A}, \mathbf{C})$ defining a threshold of $20 \%$ of the peak on either side of the peak, and Full (B,D) defining the same time duration for both based on linear and rotational $20 \%$ thresholds.

\subsection{Mouthguard}

The HitIQ Nexus A9 instrumented mouthguard (HitIQ Pty. Ltd., Melbourne Australia) is relatively new to the market, and as such has not previously undergone validation in a laboratory setting. The mouthguard included an array of three accelerometers (Analog Devices (Norwood, MA, USA) ADXL372, range: \pm 200 g, 12-bit) and a gyroscope (Bosch (Gerlingen, Germany) BMG260, \pm 2000 dps range, 16-bit), providing two independent measurements of rotational acceleration and velocity, respectively, which may allow the mouthguard to display increased accuracy and dynamic range of the angular kinematic estimates. A three-accelerometer array also provided an estimate of angular acceleration independent of the gyroscope, allowing for a cross-check to remove spurious readings originating from actions such as mouthguard deformation, rather than head kinematics. Two accelerometers were located on the outside of the first molar, on both the left and right sides of the mouthguard. The third accelerometer and a gyro were mounted on the inside of the central incisors.

The mouthguard componentry was mounted to a base layer of high-shore-rated ethylene vinyl acetate copolymer (EVA) mouthguard material that was thermoformed to a 3D-printed high-resolution dentition. It was secured to the base layer by thermoforming a hard and thin intermediate layer of styrene-butadien-styrene (SBS), which protects componentry and the users' teeth. A thicker final layer of EVA was then thermoformed over this, which reinforced the support of the intermediate layer and componentry. The bonding of the intermediate layer around the componentry, along with EVA hot melt used around componentry edges, ensured the componentry would remain in position. The base layer and final layer had enough surface area around the componentry to bond to each other under heat applied during manufacturing, ensuring that the componentry was fully encapsulated and tightly sealed within the mouthguard material. The total thickness of these layers was up to $5.8 \mathrm{~mm}$. All materials complied with the biocompatibility standard ISO10993, and were approved dental/medical grade materials.

The sensors were each located in a different orientation. As a consequence, each local reference system was rotated with respect to the reference system at the centre of the head. Calibration of the sensors was carried out using a specialized apparatus and software to compare sensors to a known reference. The gains and transformations needed to rotate each sensor's signals from the local sensor system of reference to the system of reference at the centre of the head could then be found. Subsequent to this, kinematic equations (3D) of the head were calculated to ensure that all sensors projected the same linear acceleration to the centre of the head. 


\subsection{Data Acquisition}

The headform housed four tri-axial accelerometers (Analog Devices (Norwood, MA, USA) ADXL377, range: $\pm 200 \mathrm{G}$, sensitivity: $6.5 \mathrm{mV} / \mathrm{g}$ ) for a total of 12 sensing axes. Accelerometers were configured in a standard "nine-accelerometer package" (NAP) array [51], with the three redundant sensing axes configured radially along each primary axis. The data were recorded using a NI9205 analog input module (National Instruments (Texas, TX, USA), sample rate: $20 \mathrm{kHz}, 16-\mathrm{bit}$ ) and stored via a LabVIEW program. Accelerometer data were processed to determine the linear and rotational acceleration at the centre of mass of the headform, according to the standard NAP algorithm [51]. Once a kinematic solution was found, results were projected back to the location of each accelerometer and crosschecked with their actual reading, thereby allowing identification of capture errors such as misalignment and deformation.

The gyroscope and accelerometers were sampled at $800 \mathrm{~Hz}$ and $3200 \mathrm{~Hz}$, respectively, to reflect the different spectral components of on-field impacts determined experimentally through field trials in Australian Rules, Rugby League, and American Football. A dentition, to which the mouthguard was moulded, was attached to the upper-jaw region of the headform (Figure 1). The dentition was bolted to the headform, and tightness of the bolts was checked periodically. The mouthguard had an indicative trigger level set at $10 \mathrm{G}$, and was set to record $20 \mathrm{~ms}$ of data before the first trigger and $80 \mathrm{~ms}$ after the last trigger in the event. A retrigger function allowed the capture of impact events containing complex kinematics, compared to a fixed-length window that can lose context during complex, multi-impact events. Data recorded by the mouthguard was saved temporarily to onboard flash memory. Then, that data was uploaded to the same computer that processed the NAP data. This data was referenced with the impact parameters (PLAs, impact duration, impact location, etc.).

\subsection{Post-Processing}

Time-series trace data for both linear and rotational acceleration was collected in MAT$\mathrm{LAB}$, and then was used to find the resultant linear and rotational accelerations. For each separate impact, PLA and PRA (Figure 2) were defined as the maximum values of the resultant time-series data for linear and rotational acceleration, respectively. These were used for the regression and Bland-Altman (BA) analyses. Similar to previous studies [43,52,53], the RMS error was calculated between the reference and mouthguard traces for both linear and rotational acceleration. Signals were first temporally aligned such that minimal area existed between them, following which the RMS and normalised RMS (NRMS) errors were calculated using Equations (1) and (2):

$$
\begin{gathered}
R M S=\sqrt{\frac{\sum_{i=1}^{n}\left(x_{i}^{m g}-x_{i}^{r e f}\right)^{2}}{n}} \\
N R M S=\frac{R M S}{\text { max }_{\text {ref }}} \times 100
\end{gathered}
$$

where $n$ is the number of measurements; $x_{i}^{m g}$ and $x_{i}^{r e f}$ are the measurements made by the mouthguard and reference sensors, respectively; and $\max _{r e f}$ is the peak reference acceleration. Two methods of trimming data for the RMS calculations were used. The first trimmed the data at a threshold acceleration of $20 \%$ of the peak on either side of the peak of the reference time-series trace, called 'Impact' RMS (Figure 2A,C). The second trimmed the data to start at a threshold of $20 \%$ PLA before the linear peak, and end at a threshold of $20 \%$ PRA after the rotational peak, called 'Full' RMS (Figure 2B,D). A 20\% threshold was experimentally determined to include the necessary trajectories generated by the impact rig, whilst excluding largely noisy data pre- and post-impact. The 'Impact' period was expected to be the impact part associated with the highest risk of brain injury, and has been commonly used in previous studies; however, fidelity of the 'Full' model may be 
required when investigating subconcussive impacts, in which impact energy is spread over a longer time.

\subsection{Statistical Analysis}

The statistical analysis was carried out in MATLAB (R2019) with an $\alpha p \leq 0.05$ for accepting statistical significance. Peak value correlation was assessed using linear regression, and coefficients of determination $\left(R^{2}\right)$ for linear and rotational acceleration. Bland-Altman analyses were used to assess levels of agreement (LOAs, 95\%) and assess any systematic bias of measured PLA and PRA between the reference and mouthguard [54,55]. Lin's concordance correlation coefficients (LCCC) and associated 95\% confidence intervals were also calculated to assess agreement between the two sensor systems. Paired-sample t-tests were calculated for RMS error values to assess statistically significant differences $(p \leq 0.05)$ between the 'Impact' and 'Full' RMS and NRMS. The accompanying $p$-values and effect size using Cohen's $d$ values were also calculated. A Cohen's d value of $\leq 0.2$ implies a weak effect, 0.5 implies a medium effect, and $\geq 0.8$ implies a large effect. Strength of agreement criteria for LCCC was put forward with substantial agreement at LCCC $=0.95-0.99$, and 'almost perfect' agreement at LCCC > 0.99 when compared to the lower one-sided 95\% CI [56].

\section{Results}

Differences in the peak value error between impact locations were small (mean (SD): $0.66 \%(2.28 \%)$ for relative PLA, and $-1.21 \%(-0.86 \%)$ for the difference in relative PRA error between impact locations), therefore results were pooled together. Figure $3 a-d$ display the correlation and BA scatter plots for PLA and PRA. The peak values measured by the mouthguard showed strong positive correlation with those of the reference sensors $\left(R^{2}=0.996\right.$ for PLA and 0.994 for PRA). Figure $3 b$ shows a nonsignificant bias of $-0.49 \%$ $(p=0.11)$ for PLA, and Figure 3d shows a significant bias of $1 \%$ for PRA $(p<0.05)$. Limits of agreement were similar between PLA and PRA $(+6.1 \%,-7.1 \%$ for PLA; and $+7.3 \%,-5.3 \%$ for PRA). Figure 3d shows one outlier, representing a rear boss, $40 \mathrm{~g}, 15 \mathrm{~ms}$ impact with a $13.1 \%$ mouthguard PRA underestimation.

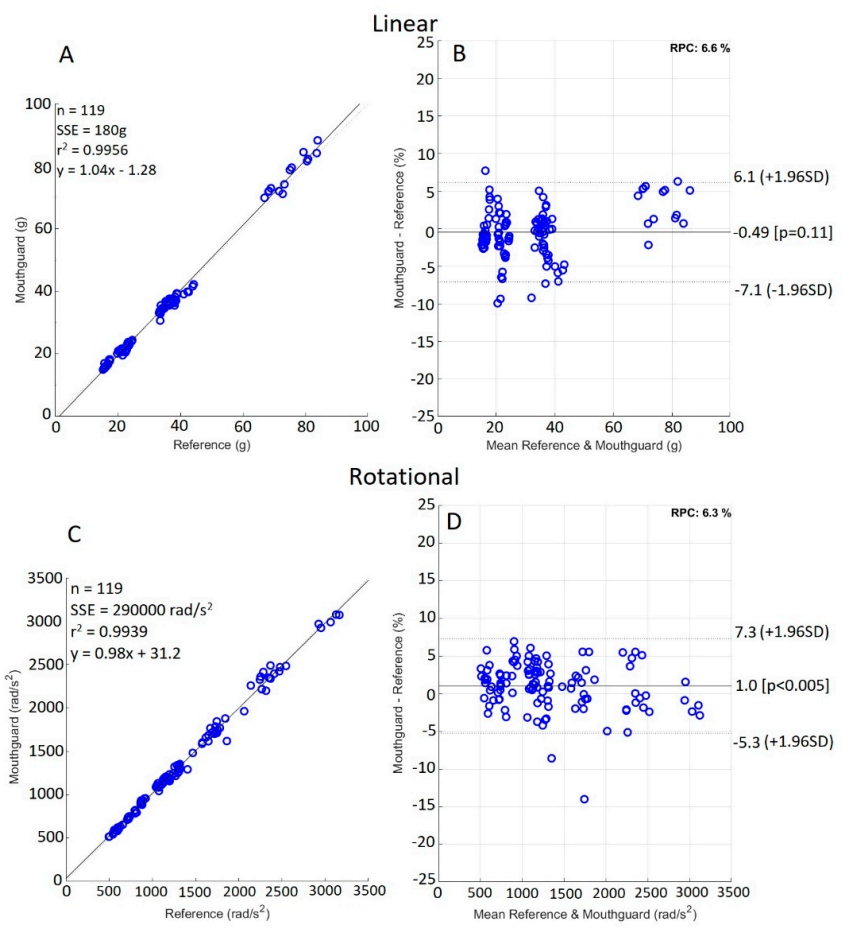

Figure 3. Correlation $(\mathbf{A}, \mathbf{C})$ and Bland-Altman $(\mathbf{B}, \mathbf{D})$ plots for PLA and PRA. 
Figure 4A-D show the 'Impact' and 'Full' NRMS errors across each impact location. In both cases for LA, one outlier was seen. The associated time-series traces are shown in Figure 5. The two time periods over which the RMS and NRMS were calculated produced different results, with the 'Full' RMS producing consistently higher RMS values for both linear and rotational acceleration. Paired-sample t-tests revealed mean differences between the two periods of $0.31 \mathrm{~g}$ for LA RMS $\left(\mathrm{t}_{(109}=5.52, p<0.05, \mathrm{~d}=0.54\right),-5.50 \mathrm{rad} / \mathrm{s}^{2}$ for RA RMS $\left(\mathrm{t}_{(109)}=1.65, p=0.10, \mathrm{~d}=0.18\right),-0.85 \%$ for LA NRMS $\left(\mathrm{t}_{(109)}=5.88, p<0.05, \mathrm{~d}=0.56\right)$, and $0.41 \%$ for RA NRMS $\left.\left(\mathrm{t}_{(109)}\right)=3.01, p<0.05, \mathrm{~d}=0.3\right)$. Figure 4 shows that there was no visible increase in the NRMS as the PLA increased. Additionally, the NRMS showed no relationship with impact duration.

Figure 5 shows the NRMS outlier, a $20 \mathrm{~g}, 15 \mathrm{~ms}$ front boss impact. This was the only outlying impact of the five recorded for that scenario. The high NRMS error was caused by the recognition of a second apparent impact after the initial peak, likely due to a minor decoupling of the mouthguard from the dentition or a slippage of the foam impact surface. This was only displayed in the linear acceleration time-series trace for this impact.

Minimal differences were found between the correlation coefficients of linear and rotational accelerations (Table 2). There was no significant difference $\left(\mathrm{t}_{(118)}=0.42, p=0.68\right.$, $\mathrm{d}=0.11$ ) between the relative peak acceleration errors for linear and rotational accelerations. Table 2 also shows the means and standard deviations of peak and RMS errors, found by taking the mean and standard deviation of all the impacts.

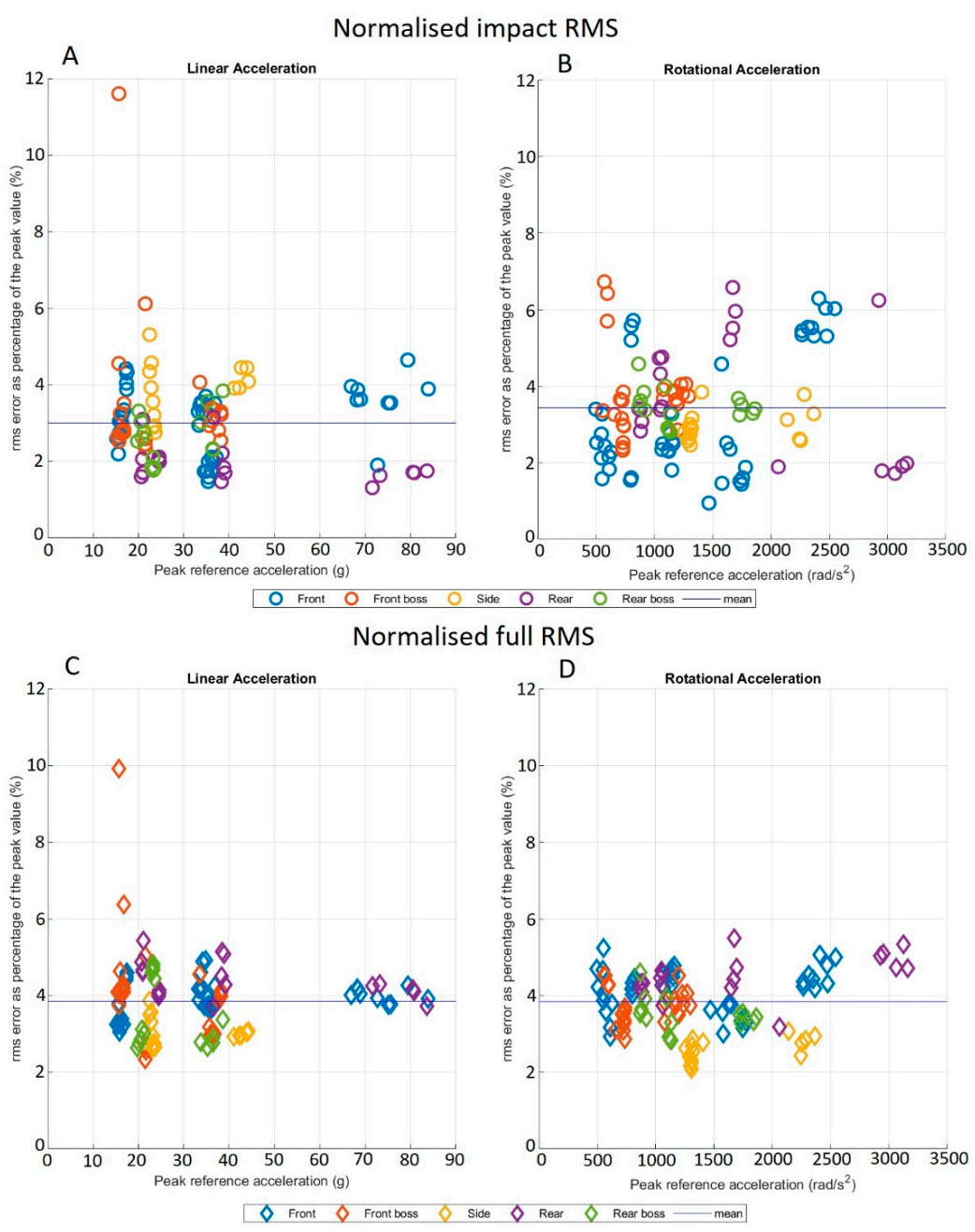

Figure 4. Normalised RMS values calculated over two different time periods for both linear and rotational accelerations. (A,B) Normalised impact RMS, (C,D) Normalised full RMS. The blue line shows the respective means. The colors show the impact location for each of the impacts. 


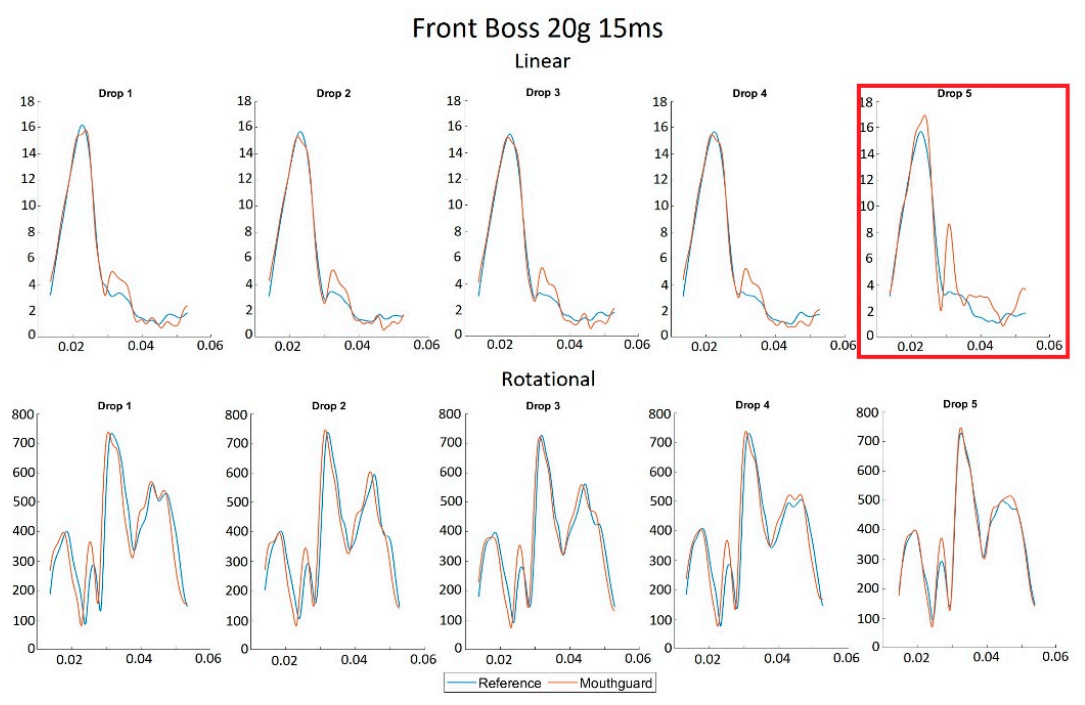

Figure 5. Each impact in the $20 \mathrm{~g}, 15 \mathrm{~ms}$ front boss scenario with the outlier marked.

Table 2. Measurement statistics.

\begin{tabular}{cccc}
\hline Metric & Measurement & Linear & Rotational \\
\hline Lin's Concordance correlation & Peak acceleration & 0.997 & 0.997 \\
coefficient & Peak acceleration & $(0.996,0.998)$ & $(0.995,0.998)$ \\
LCCC 95\% confidence interval & Peak acceleration & 0.996 & 0.994 \\
$\mathrm{R}^{2}$ value & Peak acceleration & $1.04 \mathrm{x}-1.28$ & $0.98 \mathrm{x}+31.2$ \\
Linear regression equation & Impact RMS & $0.98(0.64)$ & $47.41(34.99)$ \\
Mean (SD) & Impact NRMS & $3.01(1.22 \%)$ & $3.44(1.33 \%)$ \\
Mean (SD) & Full RMS & $1.28(0.75)$ & $52.20(31.60)$ \\
Mean (SD) & Full NRMS & $3.85(0.92 \%)$ & $3.85(0.76 \%)$ \\
Mean (SD) & Peak acceleration & $2.56(2.16 \%)$ & $2.82(2.54 \%)$ \\
\hline
\end{tabular}

\section{Discussion}

The results showed a strong linear correlation between the Nexus A9 mouthguard and the headform reference sensors for both PLA and PRA, with $\mathrm{R}^{2}$ values of 0.996 and 0.994, respectively. The mouthguard showed strong agreement with the reference sensors, with an LCCC value of 0.997 . A study conducted by Greybe et al. utilised a pendulum impactor, producing PLAs of 7-102.5 g, when comparing an intelligent mouthguard to reference sensors inside a headform [52]. The $\mathrm{R}^{2}$ values were 0.93 for PLA and 0.99 for peak rotational velocity (PRV), whilst PRA was not investigated. An earlier mouthguard validation study by Bartsch et al. utilised both a headform simulation and in vivo head impacts, producing $\mathrm{R}^{2}$ values of 0.99 for PLA, 0.99 for PRV, and 0.98 for PRA [53]. A third mouthguard validation study by Camarillo et al. reported $R^{2}$ values of 0.96 for PLA, 0.89 for PRA, and 0.98 for PRV [43]. Typically, the strongest correlation for sporting head-impact sensors are PRV values, with most studies reporting $R^{2}$ values of $0.98-0.99[40,41,43,57]$, whilst PRA tends to have a weaker correlation with reference sensors.

The BA analysis showed a nonsignificant $(p=0.11$ ) bias of $-0.49 \%$ with $95 \%$ LOA of $(-7.1,6.1 \%)$ for PLA, and a statistically significant bias of $1 \%$ with $95 \%$ LOA of $(-5.3,7.3 \%)$ for PRA. The PLA and PRA bias did not reach significance when the BA analysis was carried out with data in absolute terms (bias of $0.05 \mathrm{~g}(p=0.73)$ for PLA, and $8.8 \mathrm{rad} / \mathrm{s}^{2}$ $(p=0.06)$ for PRA). The limits of agreement were relatively narrow for both PLA and PRA, which, in combination with the LCCC value of 0.997 , showed the mouthguard to strongly agree with the measurements made by the reference sensors. In a practical application, such as field use of the mouthguard, the observed peak acceleration errors of -7 to $6 \%$ for PLA and -5 to $7 \%$ for PRA are small, and likely to be insignificant compared to other 
potential sources of error. Greybe et al. carried out a BA analysis, reporting systematic bias of $2.5 \mathrm{~g}$ and $-0.5 \mathrm{rad} / \mathrm{s}$ for PLA and PRV, respectively [52]. Very few other studies regarding sporting head-impact sensors utilised BA analysis, with most using only a linear correlation instead. BA analysis is useful for studies such as these, as it illustrates, in a more easily digestible way, the measurement errors of the device being validated, whilst exposing any under- or overestimation bias.

The furthest outlier in the present PRA BA analysis was due to an underestimation of the PRA by the mouthguard during a rear boss, $40 \mathrm{~g}, 15 \mathrm{~ms}$ impact. Unlike the outlier shown in Figures 4 and 5, the associated RMS error was low, indicating a close match of the shape of the time-series trace between the mouthguard and the reference. The RMS error was useful for investigating the shapes of the two time-series traces. This is important, as many of the metrics for determining the injury potential, such as $15 \mathrm{~ms}$ Head Impact Criterion $\left(\mathrm{HIC}_{15}\right)$, Head Impact Telemetry severity profile $\left(\mathrm{HIT}_{\mathrm{sp}}\right)$, and other kinematic injury predictors, rely on, and are sensitive to, the shape of the impact-acceleration trace. In previous studies, Camarillo et al. calculated the RMS over 25 data points $(24.4 \mathrm{~ms})$ centred about the peak of the impact, assuming this would capture the entire impact [43]. Greybe et al. used similar methodology, with the RMS being taken over the duration of the 'impact part of the trace' [52]. The longest impacts reported in this study were $23.5 \pm 6.7 \mathrm{~ms}$, with the shortest at $12.1 \pm 5.8 \mathrm{~ms}$, which were comparable with those achieved in the present study $(9.7-38 \mathrm{~ms})$. The time over which the PLA occurred does not encapsulate the time over which the PRA occurred, nor did it account for the total duration, where a significant amount of excitation existed within the acceleration trace.

For comparison with other studies, 'Impact' RMS values were used due to their shorter duration and closer resemblance to durations used in other studies. Camarillo et al. reported average RMS (NRMS) errors of $3.9 \pm 2.1 \mathrm{~g},(9.9 \pm 4.4 \%)$ and $202 \pm 120 \mathrm{rad} / \mathrm{s}^{2}$ $(9.7 \pm 7 \%)$ for linear and rotational acceleration, respectively [43]. Greybe et al. found RMS (NRMS) errors of $4.3 \pm 3.5 \mathrm{~g}(13.1 \pm 9.9 \%)$ for linear acceleration [52]. Those found for the HitIQ Nexus A9 mouthguard were smaller than those in previous literature, with RMS (NRMS) values of $1.0 \pm 0.6 \mathrm{~g},(3.0 \pm 1.2 \%)$ and $47.4 \pm 35.0 \mathrm{rad} / \mathrm{s}^{2},(3.4 \pm 1.3 \%)$ for linear and rotational acceleration, respectively. When the 'Full' time period was used for the RMS error calculation, consistently higher values were achieved, reaching statistical significance for both linear and rotational accelerations. For linear acceleration, this was likely due to the tail of the time-series data trace having a much higher signal-to-noise ratio than that across the impact peak. For rotational acceleration, however, the difference was likely due to the increased amount of large numbers in the time-series data trace across additional peaks on either side of the maximal, rather than excess noise. It should be noted that the effect sizes of the differences in RMS and NRMS errors between the impact and full durations were quite low (0.18-0.56). Similar to the systematic bias displayed in the BA analysis, in a practical setting, these RMS differences would likely be insignificant compared to potential errors from external sources.

The small RMS errors, strong linear correlation, and strong agreement between measurements made by the mouthguard and reference sensors demonstrated the high comparability of peak accelerations and shapes of the acceleration time-series traces between the mouthguard and reference sensors. This study, like those conducted previously, had its limitations. This study was conducted in a controlled laboratory, on a rigid-body headform. This differed from the conditions imposed on the mouthguard during use in sports; for example, through relative motion of the mandible [43], decoupling from the upper jaw due to saliva lubrication, or noise from nonhead impact events. The testing method only incorporated a limited range of PLA values, from 15.2-83.9 g, with a visible break in continuous values from 40-80 g (Figure 3). Rigid coupling between the mouthguard and dentition were assumed during testing and were confirmed by visual inspection after every impact. Future studies should investigate the effects of high- energy, low-duration impacts, as is seen with previous research $[43,52,53]$. Additionally, a linear impactor could be employed instead of a drop-test rig in order to replicate a greater range of impact locations and scenarios. 


\section{Conclusions}

This study revealed that the PLAs, PRAs, and shapes of the time-series acceleration data measured by the HitIQ Nexus 9 instrumented mouthguard closely matched those measured by the reference sensors inside the ATD headform. The methods for impact testing were limited, as only certain impact locations could be tested under certain scenarios with longer impact durations. The results reported in this study only hold up under the assumption that the head is a rigid body. This, however, shows promising results for accurately measuring and investigating head impacts seen in a sporting context, with lower PLA, PRA, and RMS errors than for other instrumented mouthguards previously validated in a laboratory setting.

Author Contributions: Conceptualization, D.S., N.D., N.K.; methodology, D.S., N.K.; validation, D.S.; formal analysis, D.S.; investigation, D.S.; writing — original draft preparation, D.S.; writing—review and editing, D.S., N.D., N.K., K.A.; supervision, N.D., N.K.; project administration, D.S. All authors have read and agreed to the published version of the manuscript.

Funding: This research received no external funding.

Institutional Review Board Statement: Not applicable.

Informed Consent Statement: Not applicable.

Data Availability Statement: Not applicable.

Acknowledgments: We would like to thank Ben Nizette and Saeed Ahmadizadeh for their helpful assistance.

Conflicts of Interest: The authors declare no conflict of interest.

\section{Appendix A}

Table A1. Description of foams used for testing.

\begin{tabular}{cccc}
\hline Foam Name & Thickness $\mathbf{( m m})$ & Manufacturer & Abbreviated Name \\
\hline Confor Green & 13 & Trelleborg & CG \\
Sunmate & 12 & Dynamic Systems Inc. & SM \\
LD45 & 18 & Zotefoams & - \\
LD29 & 15 & Zotefoams & - \\
HD30 & 10 & Zotefoams & - \\
EV30 & 14 & Zotefoams & - \\
LD15 & 10 & Zotefoams & - \\
LD32 & 10 & Zotefoams & - \\
Zotefoam Blue & 10 & Zotefoams & ZFB \\
Perspex & 2 & - & $\mathrm{P}$ \\
\hline
\end{tabular}

\section{Appendix B}

Table A2. Foam combinations used to achieve PLA and durations for testing.

\begin{tabular}{cc}
\hline A & CG \\
B & P, 3x SM \\
C & $3 \times$ SM, CG \\
D & CG, P, 5x SM, CG, P \\
E & EV30 \\
F & LD29 \\
G & EV30, ZFB, P, CG \\
H & Lx SM, 3x CG, EV30, ZFB, LD29 \\
I & LD32 \\
J & LV30, LD29, ZFB, LD45 \\
K & P, HD30 \\
L &
\end{tabular}




\section{References}

1. Rugby, W. Global Rugby Participation; World Rugby: Dublin, Ireland, 2017.

2. Lock, S. Number of Participants in Boxing in the United States from 2006 to 2017; Statista: Hamburg, Germany, 2018.

3. Lange, D. Number of People Participating in Boxing* in England from 2016 to 2019; Statista: Hamburg, Germany, 2019.

4. Lock, S. Number of Participants in Tackle Football in the United States from 2006 to 2018; Statista: Hamburg, Germany, 2020.

5. Gough, C. Countries by Number of Registered Ice Hockey Players in 2018/19; Statista: Hamburg, Germany, 2019.

6. Sosin, D.M.; Sniezek, J.E.; Thurman, D.J. Incidence of mild and moderate brain injury in the United States. Brain Inj. 1996, 10, 47-54. [PubMed]

7. Daneshvar, D.H.; Nowinski, C.J.; McKee, A.C.; Cantu, R.C. The Epidemiology of Sport-Related Concussion. Clin. Sports Med. 2011, 30, 1-17. [CrossRef]

8. Lincoln, A.E.; Caswell, S.V.; Almquist, J.L.; Dunn, R.E.; Norris, J.B.; Hinton, R.Y. Trends in concussion incidence in high school sports: A prospective 11-year study. Am. J. Sports Med. 2011, 39, 958-963. [CrossRef]

9. Fuller, C.W.; Taylor, A.; Raftery, M. 2016 Rio Olympics: An epidemiological study of the men's and women's Rugby-7s tournaments. Br. J. Sports Med. 2017, 51, 1272-1278. [CrossRef]

10. King, D.; Hume, P.; Cummins, C.; Pearce, A.; Clark, T.; Foskett, A.; Barnes, M. Match and Training Injuries in Women's Rugby Union: A Systematic Review of Published Studies. Sports Med. 2019, 49, 1559-1574. [CrossRef]

11. Silver, D.; Brown, N.; Gissane, C. Reported concussion incidence in youth community Rugby Union and parental assessment of post head injury cognitive recovery using the King-Devick test. J. Neurol. Sci. 2018, 388, 40-46. [CrossRef]

12. Agel, J.; Dompier, T.P.; Dick, R.; Marshall, S.W. Descriptive epidemiology of collegiate men's ice hockey injuries: National Collegiate Athletic Association Injury Surveillance System, 1988-1989 through 2003-2004. J. Athl. Train. 2007, $42,241$.

13. Agel, J.; Dick, R.; Nelson, B.; Marshall, S.W.; Dompier, T.P. Descriptive epidemiology of collegiate women's ice hockey injuries: National Collegiate Athletic Association Injury Surveillance System, 2000-2001 through 2003-2004. J. Athl. Train. 2007, 42, 249. [PubMed]

14. Rishiraj, N.; Lloyd-Smith, R.; Lorenz, T.; Niven, B.; Michel, M. University men's ice hockey: Rates and risk of injuries over 6-years. J. Sports Med. Phys. Fit. 2009, 49, 159.

15. Zazryn, T.R.; Finch, C.F.; McCrory, P. A 16 year study of injuries to professional kickboxers in the state of Victoria, Australia. Br. J. Sports Med. 2003, 37, 448-451. [CrossRef] [PubMed]

16. Estwanik, J.J.; Boitano, M.; Ari, N. Amateur Boxing Injuries at the 1981 and 1982 USA/ABF National Championships. Physician Sportsmed. 1984, 12, 123-128. [CrossRef]

17. Bledsoe, G.H.; Li, G.; Levy, F. Injury Risk in Professional Boxing. South. Med. J. 2005, 98, 994-998. [CrossRef]

18. Graham, R.; Rivara, F.P.; Ford, M.A.; Spicer, C.M.; Committee on Sports-Related Concussions in Youth. Sports-Related Concussions in Youth: Improving the Science, Changing the Culture; National Academies Press: Washington, DC, USA, 2014.

19. Bailes, J.E.; Petraglia, A.L.; Omalu, B.I.; Nauman, E.; Talavage, T. Role of subconcussion in repetitive mild traumatic brain injury. J. Neurosurg. 2013, 119, 1235-1245. [CrossRef]

20. Gavett, B.E.; Stern, R.A.; McKee, A.C. Chronic Traumatic Encephalopathy: A Potential Late Effect of Sport-Related Concussive and Subconcussive Head Trauma. Clin. Sports Med. 2011, 30, 179-188. [CrossRef]

21. Guskiewicz, K.M.; Marshall, S.W.; Bailes, J.; McCrea, M.; Cantu, R.C.; Randolph, C.; Jordan, B.D. Association between Recurrent Concussion and Late-Life Cognitive Impairment in Retired Professional Football Players. Neurosurgery 2005, 57, 719-726. [CrossRef]

22. Guskiewicz, K.M.; Marshall, S.W.; Bailes, J.; Mccrea, M.; Harding, H.P.; Matthews, A.; Mihalik, J.R.; Cantu, R.C. Recurrent Concussion and Risk of Depression in Retired Professional Football Players. Med. Sci. Sports Exerc. 2007, 39, 903-909. [CrossRef] [PubMed]

23. ACC. Sport Concussion in New Zealand; ACC National Guidelines; ACC: Wellington, NZ, USA, 2015.

24. Duhaime, A.C.; Beckwith, J.G.; Maerlender, A.C.; McAllister, T.W.; Crisco, J.J.; Duma, S.M.; Brolinson, P.G.; Rowson, S.; Flashman, L.A.; Chu, J.J.; et al. Spectrum of acute clinical characteristics of diagnosed concussions in college athletes wearing instrumented helmets: Clinical article. J Neurosurg. 2012, 117, 1092-1099. [CrossRef] [PubMed]

25. McCrory, P.; Meeuwisse, W.; Aubry, M.; Cantu, B.; Dvorak, J.; Echemendia, R.; Engebretsen, L.; Johnston, K.; Kutcher, J.; Raftery, M.; et al. Consensus statement on Concussion in Sport-The 4th International Conference on Concussion in Sport held in Zurich, November. J. Sci. Med. Sport 2013, 16, 178-189. [CrossRef] [PubMed]

26. Gardner, A.; Iverson, G.; Levi, C.; Schofield, P.; Kay-Lambkin, F.; Kohler, R.M.N.; Stanwell, P. A systematic review of concussion in rugby league. Br. J. Sports Med. 2014, 49, 495-498. [CrossRef]

27. Makdissi, M.; Darby, D.; Maruff, P.; Ugoni, A.; Brukner, P.; McCrory, P.R. Natural history of concussion in sport: Markers of severity and implications for management. Am. J. Sports Med. 2010, 38, 464-471. [CrossRef]

28. McClincy, M.P.; Lovell, M.R.; Pardini, J.; Collins, M.W.; Spore, M.K. Recovery from sports concussion in high school and collegiate athletes. Brain Inj. 2006, 20, 33-39. [CrossRef]

29. McCrea, M.; Guskiewicz, K.; Randolph, C.; Barr, W.B.; Hammeke, T.A.; Marshall, S.W.; Kelly, J.P. Effects of a symptom-free waiting period on clinical outcome and risk of reinjury after sport-related concussion. Neurosurgery 2009, 65, 876-883. [CrossRef] 
30. McCrea, M.; Guskiewicz, K.; Randolph, C.; Barr, W.; Hammeke, T.A.; Marshall, S.; Powell, M.R.; Ahn, K.W.; Wang, Y.; Kelly, J.P. Incidence, Clinical Course, and Predictors of Prolonged Recovery Time Following Sport-Related Concussion in High School and College Athletes. J. Int. Neuropsychol. Soc. 2013, 19, 22-33. [CrossRef] [PubMed]

31. Eisenberg, M.A.; Andrea, J.; Meehan, W.; Mannix, R. Time Interval Between Concussions and Symptom Duration. Pediatry 2013, 132, 8-17. [CrossRef] [PubMed]

32. Williams, R.; Puetz, T.W.; Giza, C.C.; Broglio, S.P. Concussion Recovery Time Among High School and Collegiate Athletes: A Systematic Review and Meta-Analysis. Sports Med. 2015, 45, 893-903. [CrossRef] [PubMed]

33. Field, M.; Collins, M.W.; Lovell, M.R.; Maroon, J. Does age play a role in recovery from sports-related concussion? A comparison of high school and collegiate athletes. J. Pediatr. 2003, 142, 546-553. [CrossRef] [PubMed]

34. Dziemianowicz, M.S.; Kirschen, M.P.; Pukenas, B.A.; Laudano, E.; Balcer, L.J.; Galetta, S.L. Sports-Related Concussion Testing. Curr. Neurol. Neurosci. Rep. 2012, 12, 547-559. [CrossRef]

35. Anderson, B.L.; Gittelman, M.A.; Mann, J.K.; Cyriac, R.L.; Pomerantz, W.J. High School Football Players' Knowledge and Attitudes About Concussions. Clin. J. Sport Med. 2016, 26, 206-209. [CrossRef]

36. McCrea, M.; Hammeke, T.; Olsen, G.; Leo, P.; Guskiewicz, K. Unreported concussion in high school football players: Implications for prevention. Clin. J. Sport Med. 2004, 14, 13-17. [CrossRef]

37. O'Connor, K.L.; Rowson, S.; Duma, S.M.; Broglio, S.P. Head-Impact-Measurement Devices: A Systematic Review. J. Athl. Train. 2017, 52, 206-227. [CrossRef] [PubMed]

38. Jadischke, R.; Viano, D.C.; Dau, N.; King, A.I.; McCarthy, J. On the accuracy of the Head Impact Telemetry (HIT) System used in football helmets. J. Biomech. 2013, 46, 2310-2315. [CrossRef]

39. McCuen, E.; Svaldi, D.; Breedlove, K.; Kraz, N.; Cummiskey, B.; Breedlove, E.L.; Traver, J.; Desmond, K.F.; Hannemann, R.E.; Zanath, E.; et al. Collegiate women's soccer players suffer greater cumulative head impacts than their high school counterparts. J. Biomech. 2015, 43, 3720-3723. [CrossRef]

40. Nevins, D.; Smith, L.; Kensrud, J. Laboratory Evaluation of Wireless Head Impact Sensor. Procedia Eng. 2015, 112, 175-179. [CrossRef]

41. Schussler, E.; Stark, D.; Bolte, J.H.; Kang, Y.S.; Onate, J.A. Comparison of a Head Mounted Impact Measurement Device to the Hybrid III Anthropomorphic Testing Device in a Controlled Laboratory Setting. Int. J. Sports Phys. Ther. 2017, 12, 592-600.

42. Wu, L.C.; Nangia, V.; Bui, K.; Hammoor, B.; Kurt, M.; Hernandez, F.; Kuo, C.; Camarillo, D.B. In Vivo Evaluation of Wearable Head Impact Sensors. Ann. Biomed. Eng. 2016, 44, 1234-1245. [CrossRef]

43. Camarillo, D.B.; Shull, P.B.; Mattson, J.; Shultz, R.; Garza, D. An Instrumented Mouthguard for Measuring Linear and Angular Head Impact Kinematics in American Football. Ann. Biomed. Eng. 2013, 41, 1939-1949. [CrossRef]

44. Siegmund, G.P.; Guskiewicz, K.M.; Marshall, S.W.; DeMarco, A.; Bonin, S.J. Laboratory Validation of Two Wearable Sensor Systems for Measuring Head Impact Severity in Football Players. Ann. Biomed. Eng. 2016, 44, 1257-1274. [CrossRef] [PubMed]

45. NOCSAE. Standard Performance Specification for Newly Manufactured Football Helmets. In Impact Attenuation Tests; NOCSAE: USA, 2017; Available online: https://nocsae.org/wp-content/uploads/2018/05/1501096770ND00217m1 7aMfrdFBHelmetsStandardPerformance.pdf (accessed on 8 September 2021).

46. King, D.A.; Hume, P.; Gissane, C.; Clark, T. Measurement of Head Impacts in a Senior Amateur Rugby League Team with an Instrumented Patch: Exploratory Analysis. ARC J. Res. Sports Med. 2017, 2, 9-20.

47. King, D.; Hume, P.; Gissane, C.; Clark, T. Head impacts in a junior rugby league team measured with a wireless head impact sensor: An exploratory analysis. J. Neurosurg. Pediatr. 2017, 19, 13-23. [CrossRef] [PubMed]

48. King, D.; Hume, P.; Brughelli, M.; Gissane, C. Instrumented Mouthguard Acceleration Analyses for Head Impacts in Amateur Rugby Union Players Over a Season of Matches. Am. J. Sports Med. 2015, 43, 614-624. [CrossRef] [PubMed]

49. King, D.; Hume, P.; Hardaker, N.; Cummins, C.; Clark, T.; Pearce, A.; Gissane, C. Female rugby union injuries in New Zealand: A review of five years (2013-2017) of Accident Compensation Corporation moderate to severe claims and costs. J. Sci. Med. Sport 2019, 22, 532-537. [CrossRef] [PubMed]

50. King, D.A.; Hume, P.A.; Gissane, C.; Kieser, D.C.; Clark, T. Head impact exposure from match participation in women's rugby league over one season of domestic competition. J. Sci. Med. Sport 2018, 21, 139-146. [CrossRef] [PubMed]

51. Padgaonkar, A.J.; Krieger, K.W.; King, A.I. Measurement of Angular Acceleration of a Rigid Body Using Linear Accelerometers. J. Appl. Mech. 1975, 42, 552-556. [CrossRef]

52. Greybe, D.G.; Jones, C.M.; Brown, M.R.; Williams, E.M.P. Comparison of head impact measurements via an instrumented mouthguard and an anthropometric testing device. Sports Eng. 2020, 23, 1-11. [CrossRef]

53. Bartsch, A.; Samorezov, S.; Benzel, E.; Miele, V.; Brett, D. Validation of an "Intelligent Mouthguard" Single Event Head Impact Dosimeter. Stapp Car Crash J. 2014, 58, 1-27. [CrossRef]

54. Bland, J.M.; Altman, D.G. Statistical methods for assessing agreement between two methods of clinical measurement. Lancet 1986, 1, 307-310. [CrossRef]

55. Klein, R. Bland-Altman and Correlation Plot; MATLAB Central File Exchange. Available online: https:/ /www.mathworks.com/ matlabcentral/fileexchange/45049-bland-altman-and-correlation-plot (accessed on 21 January 2021). 
56. McBride, G.B. A Proposal for Strength of Agreement Criteria for Lin's Concordance Correlation Coefficient; National Institute of Water and Atmospheric Research Ltd.: Auckland, New Zealand, 2005.

57. Tyson, A.M.; Duma, S.M.; Rowson, S. Laboratory Evaluation of Low-Cost Wearable Sensors for Measuring Head Impacts in Sports. J. Appl. Biomech. 2018, 34, 320-326. [CrossRef] 